\title{
Biodiesel production from crude Jatropha oil using a highly active heterogeneous nanocatalyst by optimizing transesterification reaction parameters
}

\begin{abstract}
Various heterogeneous catalysts are often used to produce biodiesel from non-edible crude oils. In this study a highly active heterogeneous calcium oxide $(\mathrm{CaO})$ nanocatalyst with a diameter and surface area of $66 \pm 3 \mathrm{~nm}$ and $90.61 \mathrm{~m} 2 / \mathrm{g}$, respectively, was synthesized from Polymedosa erosa (P. erosa) seashells through a calcinationï hydrationï dehydration technique. The nano- $\mathrm{CaO}$ catalysis impact was investigated in a two-step transesterification of triglycerides from crude Jatropha oil as a biodiesel along with other reaction parameters such as catalyst ratio, reaction time, and methanol to oil ratio. Fourier transform infrared spectroscopy, transmission electron microscope, X-ray diffraction, and Brunauerï Emmettï Teller spectrographic techniques were utilized to evaluate the $\mathrm{CaO}$ nanocatalyst spectral and structural characteristics. The effect of the transesterification parameters on reaction kinetics and Jatropha biodiesel (JB) yield were analyzed by employing a three-factor-five-level response surface methodology model based on a full factorial, two-block, central composite design. The adequacy of the predicted model was verified, and a 98.54\% JB yield was reported at optimal parametric conditions, i.e., 0.02:1 (w/w) catalyst ratio, $133.1 \mathrm{~min}$ reaction time, and $5.15: 1 \mathrm{~mol} / \mathrm{mol}$ of methanol to the pretreated oil. An average of $95.8 \% \mathrm{JB}$ yield was obtained from the catalyst reusability up to the sixth cycle. Fuel property test results of JB were found to be highly commensurate with the biodiesel standard EN 14214.
\end{abstract}

Keyword: Biodiesel; Jatropha oil; Heterogeneous catalyst; Catalysts 